\title{
GOVERNANDO A EDUCAÇÃO PELO ESPELHO DO PERITO: UMA ANÁLISE DO PISA COMO INSTRUMENTO DE REGULAÇÃO
}

\author{
Luís Miguel Carvalho*
}

\begin{abstract}
RESUMO: Este artigo analisa o Programme for International Student Assessment (PISA), desenvolvido sob a égide da OCDE, como um instrumento baseado e gerador de conhecimento que participa na coordenação da acção pública no sector educativo. O texto retoma as análises desenvolvidas numa pesquisa sobre a fabricação supranacional do Programa PISA, realizada no âmbito de um projecto de investigação europeu acerca do papel do conhecimento nas políticas públicas de educação e saúde na Europa - Knowandpol. Equacionando o PISA - em suas actividades de inquirição, organização e publicação - como um complexo processo de construção de um espaço de regulação política transnacional, o artigo analisa os elementos cognitivos e normativos do instrumento relacionados com a definição da "realidade educacional", com a determinação das formas "apropriadas" ao seu governo, e com a produção de conhecimento para a política.
\end{abstract}

Palavras-chave: Conhecimento educacional. Organizações internacionais. OCDE. PISA. Política educativa.

GOVERNING EDUCATION WITH THE EXPERT MIRROR:

AN ANALYSIS OF PISA AS A REGULATION TOOL

ABSTRACT: The article analyses the OECD's Programme for International Student Assessment (PISA) as a tool - knowledge-based and knowledge-generator - that participates in the coordination of public action in the field of education. The text is based on a

Professor associado da Faculdade de Psicologia e de Ciências da Educação da Universidade de Lisboa, membro da equipa portuguesa do Projecto de Investigação Knowandpol. E-mail: lmcarvalho@fpce.ul.pt 
previous research on the supranational fabrication of PISA, carried out within a large-scale European research project on the role of knowledge in Health and Education public policies - Knowandpol. The article examines PISA - and its multiple and related activities of inquiry, organization and publication - as a policy tool, and analyses its cognitive and normative features concerning tree issues: the definition of "educational reality"; the set up of appropriate forms of governing education, and the production of knowledge for policy.

Key words: Educational knowledge. International organizations. OECD. PISA. Education policy.

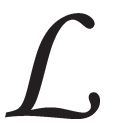

ançado em finais dos anos de 1990, o Programme for International Student Assessment (PISA) é um dispositivo de avaliação comparada internacional das performances dos escolares que se vem afirmando, ao longo da presente década, como um dos principais meios de acção da OCDE no campo educativo. A agência apresenta-o como um estudo que pretende responder às exigências dos países membros, no sentido de, com regularidade, disporem de dados fiáveis sobre os conhecimentos e as competências dos seus alunos e, consequentemente, sobre o desempenho dos seus sistemas de ensino. Este artigo analisa o PISA, precisamente, nessa sua condição de instrumento, baseado e gerador de conhecimento, que se propõe a apoiar e participar no labor de coordenação da acção pública em educação.

$\mathrm{O}$ presente texto resulta de uma das investigaçôes realizadas no âmbito da linha de pesquisa "Conhecimento como Instrumento de Regulação", do projecto Knowandpol; mais concretamente, resulta de um estudo conduzido sob os propósitos de descrever e analisar a construção do PISA a nível supranacional e as relações que o instrumento estabelece entre conhecimento e política pública (Carvalho, 2009). A pesquisa observou a produção e a difusão do Programa - em suas múltiplas componentes de inquirição, publicação e organização - como processo de construção de "conhecimento para a política", apoiandose, para tal, em literatura produzida no âmbito do Knowandpol (Delvaux \& Mangez, 2007, 2008), bem como em contributos da investigação sobre as organizações internacionais e em estudos sobre a construção social da ciência e da inovação. $O$ trabalho recorreu a um corpus documental amplo - principais publicações do PISA (e.g., Final 
Reports e Assessment Frameworks), actas das reuniões do seu órgão de orientação estratégica e de supervisão e textos de membros do Programa, com conhecidas responsabilidade na sua orientação e gestão - e mobilizou ainda fontes orais, incluindo uma entrevista com um membro da OCDE, responsável pela gestão do PISA, e um largo conjunto de entrevistas com variados actores (ministros, representantes nacionais na estrutura de direcção estratégica do Programa, gestores nacionais) de seis países europeus. ${ }^{1} \mathrm{O}$ exame destes materiais foi conduzido em torno de três eixos analíticos: (i) "o PISA como instrumento de regulação" - centrado nos elementos cognitivos e normativos do Programa, relacionados com a definição da "realidade educacional" e com a determinação das formas "apropriadas" ao seu governo; (ii) "conhecimento" - os propósitos e os meios da construção do conhecimento no âmbito do empreendimento PISA, as fontes de conhecimento ali mobilizadas e os saberes que gera; (iii) "actores e redes" - o PISA enquanto universo sócio-organizacional, a sua ecologia e a agência da OCDE, no sentido da coordenação e da obtenção de cooperação entre os variadíssimos participantes no Programa.

Este artigo inclui uma parte das perspectivas e das análises ali desenvolvidas. A primeira secção apresenta o ponto de vista a partir do qual se procurou conhecer o PISA como instrumento de regulação. O texto parte de uma primeira interpelação do Programa, por via da sua contextualização (um breve excurso histórico sobre a tradição da avaliação comparada das performances dos escolares e sobre a intervenção da OCDE no campo educacional), para depois enunciar as principais ideias orientadoras da perspectiva adoptada na investigação. $\mathrm{Na}$ segunda secção, o artigo descreve e analisa os elementos cognitivos e normativos do instrumento de regulação, focando a sua acção nos planos da definição da "realidade educacional", do estabelecimento de condutas apropriadas para o governo do sector da educação, e da constituição de conhecimento para a política.

\section{Perspectivando o PISA como instrumento de regulação}

Do conjunto de ideias recorrentemente disseminadas sobre o PISA em textos de auto-apresentação - que estabelecem as marcas da identidade do Programa, demarcando-o de projectos congéneres ou concorrentes -, sobressaem as que dão conta da natureza do empreendimento em 
Governando a educação pelo espelho do perito...

torno de seus propósitos e meios: a sua orientação para a promoção da "aprendizagem política" e o seu carácter "colaborativo".

A vocação política do instrumento é apresentada ora como uma das características centrais, ora como um dos seus objectivos centrais:

Its policy orientation, with design and reporting methods determined by the need of governments to draw policy lessons. (...) PISA will aim to better assist countries in understanding the processes that shape quality and equity in learning outcomes within the educational, social and cultural contexts in which education systems operate (...) providing a stable point of reference against which to monitor the evolution of education systems. (OECD, s.d., p. 1 e 17)

A ligação entre o propósito da monitorização e a disposição dos agentes políticos para aprenderem com os dados é sublinhada:

El propósito de PISA va mucho más allá de la simple supervisión del estado actual del aprendizaje por parte de los alumnos en los sistemas educativos nacionales. La información facilitada por PISA debía permitir a los responsables políticos observar qué factores están asociados al éxito educativo, y no limitarse a establecer comparaciones entre resultados aisladamente. (Schleicher, 2006, p. 23)

É igualmente sublinhado o seu carácter “colaborativo", reunindo disciplinadamente políticos e peritos:

PISA is a collaborative effort, bringing together scientific expertise from the participating countries, steered jointly by their governments on the basis of shared, policy-driven interests. Participating countries take responsibility for the project at the policy level through a Board of Participating Countries. Experts from participating countries serve on working groups that are charged with linking the PISA policy objectives with the best available substantive and technical expertise in the field of international comparative assessment of educational outcomes. Through participating in these expert groups, countries ensure that the PISA assessment instruments are internationally valid and take into account the cultural and curricular contexts of OECD Member countries, that they provide a realistic basis for measurement, and that they place an emphasis on authenticity and educational validity. (OECD, 2001, p. 3)

De acordo com estes textos, a mobilização do conhecimento e dos seus peritos é feita por referência quer às coordenadas estabelecidas 
pelos países membros, quer ao propósito de facilitar o acesso dos políticos a saberes relevantes. Por isso, o desenho do programa e os métodos subjacentes à feitura dos relatórios finais de cada estudo são apresentados, pelos responsáveis pelo Programa, como dependentes da necessidade dos governos extraírem daí liçōes políticas acerca da qualidade dos resultados da aprendizagem, da igualdade nos resultados da aprendizagem e equidade nas oportunidades educativas, da eficácia e da eficiência dos processos educativos e do impacto dos resultados da aprendizagem no bem-estar social e económico (OECD, s.d.; Schleicher, 2006).

Para compreendermos os elementos centrais da caracterização do Programa, avançados nos parágrafos anteriores - indicadores de performance, monitorização, orientação para a aprendizagem política, colaboração e parceria a uma escala global -, é necessário colocá-lo em perspectiva histórica, dando atenção à sua inscrição na trajectória de instrumentos similares e ao contexto organizacional no qual é gerado.

\section{O PISA em contexto}

O PISA inscreve-se numa linhagem de estudos internacionais de avaliação comparada do rendimento dos escolares, cujo ponto de partida alguns autores localizam na década de 1950 e associam ao trabalho conjunto de diversas instituições de investigação sob os auspícios da UNESCO (Bottani, 2006; Morgan, 2007). Desse esforço resultou um primeiro estudo (ver Foshay, 1962) e, porventura mais importante do que isso, dele dimanou, em 1961, uma forma organizacional - a International Association for the Evaluation of Educational Achievement (IEA) - que, durante cerca de três décadas e com os seus estudos (em diversas áreas, mas com mais regularidade nas da matemática, da leitura, e das ciências), viria a ocupar um lugar central - se não mesmo a obter o monopólio - no campo dos estudos internacionais, sobre as performances dos escolares (ver Husén \& Postlethwaite, 1996; Postlethwaite, 1999; Bottani, 2006; Mons, 2007; Morgan, 2007; Carvalho, 2009).

A entrada em cena da OCDE, através do PISA, veio a dar término à centralidade da IEA, introduzindo rupturas numa "comunidade de prática” estabelecida ao seu redor (ver Morgan, 2007); ${ }^{2}$ mas não veio, pode dizer-se, pôr fim a uma tradição. O PISA dá continuidade à opção pela medição empírica e directa das aprendizagens como o meio para a 
avaliação da eficácia dos sistemas educativos (Bottani, 2006; Mons, 2007). Mas, além disso, confirma um projecto de comparação (em Educação), no qual predomina uma razão pragmática, caracterizável seguindo o modelo analítico proposto por António Nóvoa (1998) pelo comprometimento com a construção de indicadores e standards para a decisão política, pela perspectivação da comparação como "momento da tomada de decisão", bem como, pela "crença na educação como factor de modernização/desenvolvimento".

Contudo, o Programa dispõe de características que o distinguem claramente de outros instrumentos congéneres (ver Bottani, 2006; Morgan, 2007). Umas remetem para a natureza da sua oferta, como, por exemplo, a "garantia da periodicidade" (trienal), ou a "flexibilidade" da sua aplicação, em função de uma estrutura modular. De facto, a regularidade das mediçôes e da devolução dos dados gerados - aliada à amplitude da cobertura geográfica (política e cultural) conseguida pelo Programa - constitui um dos principais trunfos exibidos pelo PISA, na medida em que permite realçar a sua capacidade de monitorização dos sistemas educativos. Ao envolverem mais de 60 países, os seus promotores podem declarar hoje que avaliam mais de um milhão de estudantes, representativos de um terço da população estudantil existente em todo o mundo e cobrindo $90 \%$ da economia mundial (OECD, s.d.; Schleicher, 2006, 2007), o que lhes permite aclamar a "pertinência universal" do instrumento (ver Hugonnier, 2008, p. 50). Outras características que permitem diferenciar o PISA de instrumentos congéneres são, porém, mais substantivas. Uma - que já abordamos em parágrafos anteriores consiste na garantia dada aos países financiadores de poderem exercer controlo sobre as prioridades do programa e a sua aplicação, organizando as actividades em torno da construção de consensos. Outra característica consiste na "originalidade" ou singularidade do seu objecto: as competências de literacia dos jovens escolarizados. Definindo "competências de literacia" como "(...) the capacity of young adults to access, manage, integrate and evaluate information, to think imaginatively, to hypothesize and discover, and to communicate their thoughts and ideas effectively" (Schleicher, 2007, p. 3).

O PISA propõe-se a apurar em que medida os jovens escolarizados de 15 anos as utilizam para apreenderem e interpretarem diferentes tipos de materiais escritos, com os quais serão confrontados no seu dia-a-dia (literacia da leitura); as empregam na resolução de desafios e problemas 
matemáticos (literacia matemática) ou na compreensão e solução de situações e desafios científicos (literacia científica). Com o recurso a provas centradas em competências de literacia e não no currículo escolar, o PISA afasta-se da tradição dos estudos internacionais vinculados a exames e/ou matérias dos programas de ensino, estabelecendo a sua área de monopólio de conhecimento em torno de um objecto singular.

A avaliação comparada não constitui uma novidade no âmbito do trabalho da OCDE. O próprio PISA emerge no contexto do projecto International Indicators of Educational Systems (INES) que a agência desenvolve desde meados da década de 1980 (ver Morgan, 2007). Porém, com o PISA, a agência "gera os seus próprios dados", isto é, não depende de dados já criados pelos sistemas nacionais, mas, ao invés, determina o quadro de questões e de orientações que a inquirição prossegue (Henry et al., 2001). Para perceber esta novidade, vale a pena revisitar, ainda que brevemente, a trajectória da acção da OCDE sobre o sector educativo.

Apesar de ser uma organização intergovernamental direccionada para uma intervenção no campo da política económica, a OCDE vem, desde a década de 50 do século passado, intervindo na esfera educativa. Neste sector, a sua acção transitou de uma intervenção centrada no desenvolvimento de instrumentos de apoio ao planeamento educacional, no contexto do investimento dos Estados na expansão dos sistemas educativos escolares, para uma outra associada à disseminação de instrumentos de apoio à monitorização da qualidade e da eficácia dos sistemas educativos (Morgan, 2007). O que parece estar hoje em causa é o governo da educação como factor gerador de vantagens na competição global e a capacidade dos sistemas educativos produzirem uma força de trabalho "flexível", capaz de responder eficazmente às necessidades do mercado de trabalho. E é a partir de uma visão que equaciona o campo educacional como parte de uma "sociedade baseada no conhecimento" que a OCDE se propóe - com o PISA - a diagnosticar e promover o desenvolvimento de competências dos escolares, pensando na sua "plena inserção" nesse espaço social imaginado.

Situando o PISA no âmbito da intervenção da OCDE no sector educativo, pode-se, portanto, fixar esta primeira ideia central: o empreendimento desenvolve-se no contexto de uma nova política educativa desta agência, marcada pela bandeira da "monitorização da qualidade" (Rinne, Kallo \& Hokka, 2004). Para tal, vem a OCDE recorrendo a ferramentas diversas - estatísticas, comparações internacionais, identificação 
de boas práticas e de boas políticas. Desenvolver estes instrumentos, vocacionados para "ajudar a decisão política", constitui, aliás, um papel assumido pela organização, como lembra o seu director-adjunto do Departamento de Educação:

[PISA] (...) développé par l'OCDE répond à cette exigence. L'objectif the nombreux pays est désormais d'améliorer la gouvernance publique et d'introduire peu à peu une culture d'évaluation. Être à même de comparer les investissements avec les résultats est donc indispensable. En mesurent les performances des élèves, PISA rend possible cette comparaison. Par ailleurs, en apportant nombre d'éclairages sur les pratiques en vigueur dans les pays participants, PISA offre la possibilité de mieux comprendre la nature des problèmes et d'identifier des réformes possibles. (Hugonnier, 2008, p. 48)

Uma outra ideia central a reter acerca da acção da OCDE no campo educacional respeita ao modo como exerce o seu papel de actor político independente (Henry et. al, 2001). A OCDE difere de outras organizações que operam a uma grande escala por não recorrer a instrumentos legais nem financeiros e por agir, sobretudo, através da "construção de consensos" e da "pressão pelos pares" (Rinne, Kallo \& Hokka, 2004, p. $455-$ 456). A capacidade da OCDE para desenvolver e dar forma às decisões políticas revela-se segundo duas modalidades: através de uma governança pela "coordenação", fazendo convergir actores diversos em iniciativas comuns, como conferências ou projectos; através da "formação de opinião", mediante um trabalho de produção de visões e de valores, de modelos e conceitos, que lhe permite iniciar e influenciar os discursos nacionais em matéria educacional (Leuze, Martens \& Rusconi, 2007).

Em suma, em vez de comandos ou de directivas, predominam as práticas de uma regulação política soft, onde sobressaem a construção de regras, a monitorização e a construção de agendas para as políticas (Jacobson \& Sahlin-Anderson, 2006; Mahon \& McBride, 2008). Estas práticas manifestam-se em actividades "meditativas" e "inquisitivas". No primeiro caso, as estruturas e processos de intervenção dos Estados modernos são debatidos por experts, e aí se fixam standards e se propõem modelos inovadores. No segundo caso, os Estados envolvidos dispóemse a mostrar-se aos outros e a submeterem-se à examinação, através de auditorias, avaliações, rankings (Jacobson, 2006, p. 207-208).

O PISA é um bom exemplo dessa intervenção da OCDE. Combinando actividades de "inquisição" e de "meditação", o Programa é palco 
da promoção de acordos, acerca de quais são as práticas e as políticas educacionais que os governos nacionais "admitem submeter a escrutínio externo", e municia regularmente os políticos de dados e análises elaborados a partir de modelos construídos com base em convenções estabelecidas entre peritos.

\section{O PISA como instrumento de regulação}

Encontramos no PISA as características de um "instrumento de acção pública” (Lascoumes \& Le Galès, 2004) que reúne e entrelaça componentes técnicas (medida, cálculo, procedimento) e sociais (representações, símbolos) e que tanto é portador de representações e de problematizações específicas do universo educativo, como participa na organização das relações sociais específicas entre actores, introduzindo regras, normas, procedimentos que intentam dar estabilidade e previsibilidade à acção colectiva e individual no universo educativo.

Assim, os indicadores da literacia matemática, científica, de leitura, entre outros, que o PISA providencia não são, nestas páginas, entendidos como sinalizadores da capacidade que os países avaliados têm para promoverem aprendizagens nos seus sistemas escolares. O que interessa a este texto são: as regras e as normas que o PISA fixa ou induz; as formas "adequadas" de prover educação que põe em equação; o exercício de mútua observação em que coloca - regularmente - os decisores políticos num espaço "competitivo-cooperativo" mundial.

Apesar das variadas e continuadas controvérsias em que tem sido envolvido, ao longo da sua curta história, o PISA - e sobretudo os seus "resultados" - vem circulando e vem-se instalando na acção pública, seja galvanizando debates, seja legitimando medidas políticas. De tal modo, que o acrónimo parece emergir como uma incontornável categoria do léxico do "planetspeak educacional" (Nóvoa, 2002) hodierno. ${ }^{3}$ Ao longo deste artigo, o empreendimento PISA é entendido como parte de um universo de conhecimento relativo à avaliação comparada dos sistemas educativos. Nessa qualidade hospeda um conjunto de tópicas - como equidade, eficácia, qualidade, empregabilidade - que dão segurança à crença, segundo a qual, parafraseando Lindblad e Popkewitz (2005, p. xx-xxi), "uma certa mudança educacional pode levar cada nação ao mundo novo global - a sociedade baseada no conhecimento". O PISA capitaliza e participa na construção de um ambiente cultural e 
político marcado pelas concepções da "competitividade económica global" e do papel decisivo da educação ou da qualificação (Broadfoot, 2000), bem como pelo pressuposto de que as avaliaçôes comparadas enquanto tecnologias de accountability - constituem o recurso mais pertinente para promover a eficácia dos sistemas educativos e, consequentemente, a competitividade económica (Rochex, 2006).

Sem esquecer a variabilidade de formas, conteúdos, amplitude e intensidade da recepção e uso do PISA, em função das especificidades nacionais (ver, e.g., Steiner-Khamsi, 2003, 2004; van Zanten, 2004; Rautalin \& Alasuutari, 2007; Grek, 2009; Carvalho, Afonso \& Costa, 2009), o presente artigo observa e analisa o Programa nessa sua qualidade de instrumento portador de modos específicos de pensar a "realidade educativa” e de regras que introduzem orientação, coordenação e controlo nas acções e nos actores do sector educativo. Portanto, o PISA é aqui analisado enquanto uma "tecnologia política" (Ozga \& Grek, 2007; Grek, 2009) que toma parte na fabricação das pessoas para uma sociedade (global) imaginada, bem como na geração de formas particulares para o seu governo, assentes em dispositivos "baseados no conhecimento".

As organizações internacionais (neste caso a OCDE) participam activamente na construção de "espaços multilaterais", para a criação e troca desse "policy knowledge", isto é, desse conhecimento que é declaradamente construído para "ajudar os decisores políticos a compreenderem causas e consequências das suas acções” (Rutkowski, 2007, p. 237; Henry et al., 2001). Este espaço multilateral é, pois, um espaço inter-organizacional, composto por organizaçóes que competem e cooperam no universo do "empréstimo" de políticas educacionais (ver Steiner-Kahmsi, 2004). Assim, importa notar: (a) que esse labor não envolve apenas a produção de conhecimento - requer também a criação de condições para a circulação e para o uso do mesmo por diversas audiências; (b) que o sucesso do empreendimento de criação de "conhecimento para a política” depende quer da credibilidade conseguida em espaço científico, quer da relevância atribuída e da maneabilidade nele percebida pelas audiências políticas (Lindquist, 1990; Rutkowski, 2007; Nahessi, 2008; Carvalho, 2009). Como escrevem Noaksson e Jacobsson (2003, p. 42), o sucesso da agência da OCDE repousa na sua validação como expert organization. Ou seja, a sua autoridade depende de uma performance de organização, livre de pontos de vista políticos e de circunstâncias particulares, capaz de produzir conhecimento para 
todos, a partir de estudos empíricos fundados em saberes sobre os quais existe um relativo consenso científico. Disso depende, como dizem os mesmos autores, a sua credibilidade, enquanto truth-teller.

Observando a "estrutura formal" do PISA, rapidamente percebemos que reúne mundos sociais muito distintos: experts nas matérias avaliadas e em metodologias da inquirição científica; investigadores associados a centros de investigação e/ou avaliação (públicos e privados); profissionais da OCDE (gestores e analistas); governantes e técnicos da administração da educação de múltiplos países. E há mais "mundos" envolvidos no empreendimento, desde os media aos intervenientes na acção pública que invocam o PISA nos debates sobre educação. No nosso estudo preocupou-nos, sobretudo, captar a "capacidade" do instrumento para habitar e para manter em cooperação esses mundos sociais tão diversos (Carvalho, 2009; Barroso \& Carvalho, 2009). E fá-lo de tal modo, que não só parece sobreviver, como apresenta expectativa de vida (até 2012 e depois) e de "desenvolvimento" (alargando o espectro das performances que estuda e o quantitativo dos países dispostos a participar). O que nos mereceu atenção foi - retomando, grosso modo, a noção de boundary objects (Star \& Griesemer, 1999, p. 509) - a sua constituição como instrumento susceptível de habitar em diferentes mundos sociais (portadores de distintas visões e usos do próprio PISA e do conhecimento que o gera e que faz gerar) e de aparentemente satisfazer, em cada um deles, suas necessidades de informação e de intervenção na regulação do sector educativo.

Assim, perspectivamos a construção deste conhecimento para a política como envolvendo um conjunto de diversas "práticas interdependentes" - na linha do proposto por Bruno Latour (1996): construção de "objectos"; estabelecimento de um "monopólio de competência" (face a outros saberes, agendas de conhecimento e produtores de conhecimento); "convencimento" de outros actores (políticos, burocratas, experts, investigadores), de modo a garantir os recursos (informacionais, financeiros, humanos) necessários à prossecução do empreendimento; assegurar a "confiança pública". No nosso estudo, os processos de fabricação do PISA foram concebidos e analisados no cruzamento de duas dimensões: social e cognitiva. A primeira refere-se à criação e estabilização de processos de organização, de cooperação, entre os múltiplos mundos sociais envolvidos no Programa. A segunda diz respeito às escolhas e definiçóes acerca do que conta como conhecimento para a 
política (e dos modos de produção e dos conteúdos que compreende), bem como acerca de uma visão para educação e dos modos como esta pode/deve ser governada (Carvalho, 2009). O texto explora, nas páginas seguintes, esta segunda dimensão da análise do instrumento.

\section{Analisando a dimensão cognitiva do instrumento de regulação}

As concepções, os critérios e os indicadores pelos quais as sociedades nacionais, os sistemas educativos e os desempenhos dos estudantes são descritos, comparados e avaliados, no âmbito do PISA, operam a um nível ontológico (Alasuutari, 2005). Entendemo-los aqui como categorias discursivas, em linha com a reflexão de Popkewitz (2000, p. viii): “(..) discursive practices whose distinctions and categories order the world, define the places of individuals, and establish rules and standards by which expression and practices are made possible".

Debruçamo-nos sobre esses elementos cognitivos e normativos do PISA, através de três "golpes" analíticos, considerando: a definição da "realidade educacional"; a definição das condutas apropriadas para o governo do sector da educação; e a construção de conhecimento para a política.

\section{Redefinindo categorias da escolarização}

O PISA é um dispositivo de monitorização comparada que delineia uma forma de olhar e de agir na educação. Essa acção exerce-se sobre categorias particulares da escolarização, senão mesmo sobre todo o aparato escolar.

Convém recordar que o PISA traz um novo enfoque para as avaliações internacionais: "rather than examine mastery of specific school curricula, PISA looks at students' ability to apply knowledge and skills in key subject areas and to analyse, reason and communicate effectively as they examine, interpret and solve problems" (PISA website).

Este enfoque provoca um deslocamento da inquirição para fora do espaço estrito das disciplinas escolares e dos saberes dos programas escolares. Este deslocamento é, em si mesmo, um duplo afastamento: (i) por um lado, das escolhas nacionais sobre as matérias de ensino e sobre as aprendizagens por matéria de ensino; (ii) por outro lado, dos 
estudos anteriormente efectuados por outras agências (por exemplo, os estudos do IEA). Este movimento permite ao projecto PISA uma dupla distinção: com a convencional reflexão dos sistema escolares sobre si mesmos; com a estabelecida conceptualização dos estudos científicos comparados sobre as performances dos alunos na dependência das categorias próprias aos sistemas educativos. Por fim, e paralela a esta diferenciação, produz-se uma reavaliação do conhecimento escolar. Como escreve Mangez (2008, p. 102-104), a noção de competência sanciona uma perspectiva utilitarista do conhecimento, na medida em que faz da "utilidade" (utilização para resolver problemas do dia-a-dia) o critério para a avaliação do saber escolar. Ela permite, assim, uma reestruturação da composição curricular, não nos termos convencionais - das "disciplinas" -, mas em termos de cruzamento disciplinar ou transdisciplinar.

A noção de competência de literacia entrelaça-se, por outro lado, com uma perspectiva científica particular sobre a aprendizagem, cuja adopção legitima à luz das mudanças da economia. A necessidade de uma passagem de uma teoria comportamental da aprendizagem, para uma teoria cognitiva da aprendizagem, tem sido enfatizada por aqueles que reclamam a adaptação do sistema escolar às mutaçóes da economia, do industrialismo para o pós-industrialismo. ${ }^{4} \mathrm{O}$ quadro de referência do PISA faz eco dessa orientação, como se pode ler na justificação da abordagem que é seguida no estudo das "competências da literacia científica":

This approach was taken to reflect the nature of the competencies valued in the modern societies, which involve many aspects of life, from success at work to active citizenship. It also reflects the reality of how globalization and computerization are changing societies and labour markets. (...) This analysis shows that the steepest decline in task input over the last decade has not been with manual tasks, as often reported, but with routine cognitive tasks, i.e. those mental tasks that are well describe by deductive or inductive rules, and that dominate many of today's middle-class jobs. This highlights that if students learn merely to memorize and reproduce scientific knowledge and skills, they risk being prepared mainly for jobs that are disappearing from labour markets in many countries. In order to participate fully in today's global economy, students need to be able to solve problems for which they are no clear rule based solutions and also communicate complex scientific ideas clearly and persuasively. PISA as responded to this by designing tasks that goes beyond the simple recall of scientific knowledge. (OECD, 2007, p. 33) 
As consequências da adopção de uma perspectiva cognitivista traduzem-se em descrições e proposições acerca de mudanças nos modos de organizar o ensino-aprendizagem: do aprendiz "passivo" e "encorajado a ser passivo" ao aprendente "experimentador e empenhado"; do professor que informa e corrige, no interior de uma "estrutura hierárquica de aprendizagem", ao professor que recorre a modelos orgânicos (como o branching e o networking) e que "devolve autoridade e responsabilidade" ao aluno; da exterioridade do conhecido (corpos de conhecimento sequencialmente transmitidos) à interioridade da construção do conhecimento, em que a aprendizagem começa com o estabelecimento pelo aluno de uma "conexão com a aquilo que já sabe" sobre o que vai estudar (acompanhando Weers \& Kerchner, 1996, p. 147).

Estes deslocamentos discursivos não atingem apenas categorias particulares da escolarização. Implicam a própria escolarização no seu conjunto. Conectando directamente a aprendizagem, os contextos e os modos de ensinar/aprender, com as "exigências" do ambiente do sistema escolar, os indicadores do PISA firmam o olhar e o debate sobre os efeitos dos sistemas escolares, não ao redor dos resultados, mas em torno das suas consequências (sobre outros sistemas). A "caixa negra" que pretendem abrir é a instituição escolar, cujo fechamento se manifesta, argumentam, na perpetuação de práticas de (auto) descrição e de (auto) avaliação que apenas consideram os seus inputs e/ou os seus outputs (resultados de testes e de exames a partir dos objectivos e conteúdos das matérias de ensino). A “visão PISA" é a de que a escolarização não deverá, portanto, ter o seu produto avaliado por referência a si mesma e às suas categorias convencionais. Antes, deve pensar-se em função das consequências do que faz, prestando assim contas (aos outros sistemas) daquilo que faz.

Ao introduzir um questionamento de práticas e cerimoniais avaliativos da instituição escolar ou das modalidades "tradicionais" de organizar o ensino-aprendizagem, o PISA pode ser percebido, por muitos actores sociais, como portador de um potencial de mudança, como força crítica e de desinstitucionalização. Mas ele constitui - simultaneamente - uma proposta de reescrita do modelo escolar, uma semântica que dirige a sua adaptação às lógicas da sociedade e da economia do conhecimento (e respondente a estas), ou mesmo de uma mais ampla reescrita do modelo educativo das sociedades contemporâneas. 


\section{Os decisores políticos como aprendizes e a comparação como forma de governo}

O PISA, em suas modalidades de organização, de inquiriçãao e de publicação, incorpora e cria espaços para as políticas da cognição, ou seja, para a agência sobre as visōes do mundo, as percepçōes da realidade e as preferências. Essa intervenção do PISA não se esgota na problematização da "realidade educativa". Exerce-se também no campo da reordenaçãa da acção dos seus potenciais utilizadores - em particular, dos decisores políticos nacionais.

O universo discursivo do PISA incorpora e expressa modos de pensar e de fazer interiorizáveis pelos actores políticos, para que eles se percebam capacitados para participar "naturalmente" nos exercícios de monitorização e de comparação internacional, tomados estes como práticas correntes e apropriadas às suas identidades e papéis. Neste quadro, o PISA pressupõe e define, também, um certo tipo de decisor político e um certo tipo de racionalidade política.

Em elocuções que descrevem e avaliam as relações dos políticos com o próprio PISA, podemos encontrar essas regras que qualificam/ desqualificam o decisor político. Seguimos, para tal, uma entrevista concedida por Andreas Schleicher à revista Veja, editada sob o sugestivo título "Medir para avançar rápido":

(...) o Brasil passou a ter chance de avançar no momento em que começou a mapear os problemas de maneira objectiva - e não mais com base na intuição de alguns governantes. Isso é básico. Não dá sequer para melhorar algo que não foi sequer dimensionado. Daí a importância da comparação internacional. Ao olhar os rankings, pais, educadores e autoridades podem começar a fazer comparaçôes e constatar o óbvio: suas escolas estão bem atrás das dos países da OCDE. (...). Ao saberem do fiasco nos últimos rankings, alguns políticos e especialistas de mentalidade mais atrasada me ligaram revoltados. Diziam: "Vocês estão exigindo dos alunos que falem sobre situaçôes distantes demais da realidade deles. É injusto". A miopia dessa gente impede de enxergar que o fato de estudantes chineses ou americanos terem resposta para tais questôes não revela apenas o despreparo dos brasileiros, mas mostra também como eles estāo em desvantagem na competição com os demais. (...). Apenas há pouco tempo, as autoridades passaram a usar esse medidor tão eficaz para aferir as próprias deficiências e apontar saídas com base em experiências que dão certo noutros países. (...). Os chineses não demonstram constrangimentos 
em copiar o que funciona noutros países. Ao contrário: eles são movidos por isso (...). A China, evidentemente, ainda tem muito que melhorar na educação - mas avança a um ritmo veloz. (Schleicher, apud Weinberg, 2008, p. 20-21)

Do ponto de vista de quem dirige o PISA - mas que, para efeitos desta análise, corporiza e expressa o conjunto de pressupostos que estabelecem a apropriada conduta do actor político no universo da agência OCDE -, o bom decisor político é aquele que: governa diagnosticando de modo objectivo o seu mundo ou sector; se orienta pela procura de vantagens competitivas através da medição dos outcomes do sistema escolar; identifica fragilidades e adopta soluções a partir do what works em outros países; conhece e copia os competidores para poder progredir mais rapidamente. O bom político é também o que dá ao sector da educação "prioridade" política e que a pensa pela razão económica, ou seja, rege-se pelo princípio da competitividade (viu-se atrás), pondo em marcha medidas "eficazes", e gere com "eficiência" as verbas orçamentais para o sector educativo. O bom decisor político não é apenas o que gere o sistema, mas, sim, aquele que: muda o sistema; tira o sector educativo do "atraso" - por comparação com outros sectores tomados como equivalentes; faz o seu sector "produzir" mais e melhor; movendo-o do "modelo industrial" para o modelo "pós-industrial" (ver Weinberg, 2008).

É dentro desta teia de causas e efeitos, de condições e de consequências (presentes e futuras), que a acção dos políticos é compreendida e que os critérios para a avaliação das suas condutas são fixados:

Nous vivons à l'heure de l'économie de la connaissance et de la mondialisation. L'une et l'autre exigent une plus haute efficience des services publics, ce qui ne peut être atteint que si l'ont peu comparer les investissements réalisés avec leurs résultats, et si les décisions politiques sont en pleine connaissance de cause. PISA répond à ces deux exigences en fournissant des informations inédites sur les performances comparées de leur système éducatif. (...) Sans ces informations (...) les décisions politiques fondées davantage sur des perceptions que sur les réalités présentent de forts risques d'échec, avec les coûts considérables en termes financiers mais aussi humains que l'ont peut imaginer. (Hugonnier, 2008, p. 61)

Neste contexto argumentativo, os "resultados do PISA" são apresentados como capazes de fornecer ao decisor político uma base de 
comparação "segura", para conhecer não apenas o lugar do "seu" sistema educativo em um espaço competitivo mundial, mas também o seu lugar numa linha do tempo (que vai da sociedade industrial à sociedade do conhecimento). Com os "dados PISA" e os modos de pensar o Programa, os decisores políticos podem orientar os seus próprios movimentos e podem fazer mover o seu país para o "tempo" (físico e simbólico) do "mundo de amanhā". Com, ou através do PISA, o decisor político racional é aquele que governa com/através de uma razão comparada e a mútua vigilância é a regra para o bom governo (ver Nóvoa \& TarivMashal, 2003).

\section{A montagem e a flexibilidade do "conhecimento para a política"}

Os documentos difundidos no âmbito do PISA - mormente aqueles que divulgam dados e análises - são preparados sob certas convenções acerca de "o que é conhecimento para a política". Eles podem ter vários propósitos, como, por exemplo: permitir que os governos possam monitorizar os seus sistemas educativos, apoiados em mediçôes consistentes e confiáveis das performances dos estudantes; ou gerar conhecimento acerca de "questôes decisivas" em matéria de sucesso educativo e dos seus meios de criação e difusão desse conhecimento -, através de "um esforço colaborativo" que reúne experts e políticos. Quando analisamos as afirmaçôes contidas nesses documentos acerca destes propósitos, percebemos que a sua lógica vai para além dos pressupostos da tradicional visão "racionalista" acerca das relações entre conhecimento e política. ${ }^{5}$ Apesar de incorporados nos textos do PISA, essas regras não são os ingredientes únicos. Mais ainda, são reconfiguradas no interior de uma lógica diferente. Salientamos, seguidamente, três elementos de transfiguração.

Primeiro: o ponto de partida dos inquéritos do PISA é parcialmente definido por outros que não os investigadores e o trabalho desenvolvido ao longo da trajectória de cada ciclo do Programa pode ser alvo de escrutínio pelos políticos. Segundo: a produção de conhecimento envolve vários grupos de investigadores, especializados em áreas diversas, que colectivamente validam a sua expertise. Terceiro: os resultados das pesquisas não são trabalhados de modo a oferecer a solução do conhecimento ao problema da política, mas de modo a facilitar uma 
relação de aprendizagem entre a audiência e o conhecimento disponibilizado. Dito de outro modo, os dados e as análises são preparados de modo a serem usados pelo decisor político, ao qual se atribui a responsabilidade de contemplar, de analisar, de reflectir e, daí, de extrair lições para a política pública. Portanto, não se trata de aproximar "linguagens", mas já de engajar os políticos em relaçóes específicas de criação de conhecimento a partir do conhecimento disponibilizado.

Associamos estes três elementos à mutação das "regras do jogo" da fabricação de conhecimento para a política. Mudança esta já retratada em literatura dedicada à análise das narrativas dos peritos contemporâneos (Nowotny, Scott \& Gibbons, 2001) e que sublinha a disposição destes para a produção de um conhecimento "transgressivo", "colectivo", fundado na "auto-organização" e na "auto-autorização". Mas associamos também esses elementos a imperativos de acção da própria OCDE, cujo sucesso não depende só das actividades de produção e de difusão de conhecimento; requer, também, a manifestação das capacidades de agir e de ser reconhecido como gerador de um conhecimento que deve ser, ao mesmo tempo: credível em universos científicos, mas manuseável pelas audiências políticas; percebido como portador de uma visão inovadora e independente da realidade educacional, mas assente em consensos.

Este conjunto de características e tensões é observável quer nos processos de inquirição, quer nos principais relatórios publicados (OECD, 1999, 2001, 2003, 2004, 2006, 2007). Estas tensões revelamse naquilo que designamos por processos de "montagem" (assemblage) do conhecimento e pelo carácter "flexível" - ou pela plasticidade - do conhecimento PISA (Carvalho, 2009). Eis alguns exemplos.

O Programa cria e difunde, primariamente, conhecimento sobre as performances e o empenhamento dos estudantes, sob o enquadramento conceptual das "competências de literacia". É isto que diferencia o "conhecimento PISA" daquele que é gerado em empreendimentos que com ele podem competir. A elaboração deste conhecimento depende de um conjunto de fontes e de produtores (e.g., conhecimento proveniente de estudos/experts na leitura, na matemática, no ensino das ciências, proveniente da estatística, da psicometria e da avaliação comparada). Embora seja "disciplinada" pelo quadro conceptual das "competências de literacia” e pela validação da comparabilidade construída 
no mundo da psicometria, a literacia é, porém, construída diferentemente em cada um dos domínios (leitura, matemática, ciências). Essa variabilidade depende de vários factores: do maior ou menor consenso obtido no interior de cada grupo de especialistas; da sua permeabilidade a factores e pressões político-culturais (nomeadamente introduzidas pelos representantes dos países-membros no órgão de direcção do PISA); da sua maior ou menor afinidade com as categorias discursivas empregues pela OCDE na legitimação da universalidade do seu projecto de avaliação comparada das performances, por exemplo, com o racional da economia global e da sociedade do conhecimento.

Nos Relatórios Finais publicados pela OCDE, no final de cada ciclo PISA, as "evidências" sobre as performances dos alunos (material primário e singular do Programa) são trabalhadas em relação com variáveis contextuais. Esta é uma segunda área de "conhecimento" sobre a realidade educativa, para a qual outros ramos de saberes são mobilizados (análise e avaliação de políticas e estudos sobre a eficácia das escolas) e na qual o saber singular do PISA é reunido com factores associados, pelos analistas, às estruturas dos sistemas educativos e às escolhas dos políticos. Várias mudanças têm ocorrido neste espaço de conhecimento. Destacamos duas: (1) a criação de um território analítico especificamente associado a elementos centrais do discurso actual da OCDE - o par "equidade/qualidade" - e no qual a oposição entre "eficiência social" e "equidade social" é transformada em matéria de "prova" técnico-científica; (2) a importância adquirida por um conjunto de factores, cujos conteúdos retomam temas centrais das mudanças da regulação das políticas públicas nas últimas décadas: autonomia das escolas, accountability, privatização, livre escolha da escola, melhoria da escola...

Podemos observar que, no interior de cada uma destas publicações, a par de um saber usado para desenvolver o survey PISA, emerge outro conhecimento gerado pelos actores que trabalham os resultados dos inquéritos. Os relatórios incorporam o primeiro, mas também lhe dão uma outra magnitude e natureza. Nos relatórios, o trabalho que prepara os surveys - e.g., preparação dos quadros conceptuais, construção da instrumentação de recolha ou de análise estatística - é transformado em "resultados", em "análises" e em "implicaçôes". Noutros termos, os relatórios mobilizam e fixam conhecimento gerado ao longo da inquirição, mas prolongam-no e associam-no a novos sentidos. O 
conhecimento PISA é aproximado da audiência, movendo-se da revelação para a condensação. Os materiais centrais e originais do PISA (as performances dos estudantes e os perfis de competência de literacia de estudantes e países) dão lugar, seguidamente, à análise da sua variabilidade em função de relações estabelecidas com factores de contexto (e.g., estatuto socioeconómico dos estudantes) e com factores dependentes da decisão política nacional. Depois, terminam em conclusõeschave e com a identificação de "factores" que devem ser tomados em consideração como questões políticas cruciais. Tudo isso feito não sob a forma de um texto prescritivo, antes redigido como um script destinado à análise, à avaliação e à reflexão dos políticos.

Sublinhe-se pois, para finalizar, o carácter estruturado e estruturável do conhecimento mobilizado para o PISA e gerado no seu interior. Trata-se de uma montagem - resultante de contingências e de estratégias - onde estão inscritas ideias e actores sociais diversos, como, por exemplo: a perspectiva pragmática dos estudos comparados; a tradição da ciência positiva; os sofisticados métodos quantitativos da psicometria; os consensos pré-existentes ou gerados no interior das comunidades e entre as comunidades de saberes especializados em matemática, leitura e ciências; o universo dos discursos sobre as sociedades contemporâneas; o estabelecimento de consensos entre os actores políticos acerca do que admitem ver/ter (mutuamente) escrutinado, e entre estes e todos os experts. Esta montagem e as relaçóes que a suportam fazem pensar nas "competências de literacia" como um objecto sempre actualizável. Não obstante, elas se afirmam (e com elas o PISA) como um ponto de origem e de chegada das políticas: um ponto a partir do qual as políticas se podem/devem orientar e para onde se podem/devem orientar.

\section{Fecho: a mútua vigilância pelo espelho do perito}

(...) we are more like a mirror. We have a mirror; you can look at it and you can see how the world looks; if you don't like it you don't look at it. ${ }^{6}$

Os relatórios do PISA são apresentados pelos seus promotores - ou querem ser percebidos - como um espelho que "apenas" revela, com limpidez e nitidez científica, "a realidade" das performances dos escolares e de suas relações com os seus backgrounds socioeconómicos e com os 
factores de mediação (de intervenção política). Para quem dirige o Programa, o que mais importa é que este seja reconhecido como ponto de passagem obrigatório para um debate e uma decisão política centrados em evidências científicas - criando "novos" problemas e disponibilizando novas informaçooes "baseadas em evidências" - e, não tanto, ser uma instância que resolve problemas (ver Carvalho, 2009). Os surveys e os relatórios do PISA são parte fundamental da exibição - pela OCDE - de uma capacidade constante de produção de inovação nos discursos políticos nacionais, de introdução de rupturas com os estereótipos da acção pública e de diferenciação face às ideias políticas nacionais.

Pelo que argumentamos em momentos anteriores deste texto, o "espelho do perito" traz consigo muito mais que uma simples devolução da realidade. A realidade devolvida pelo espelho compreende, articula e difunde regras acerca da educação, da escolarização e das relaçōes entre estas e a economia e a sociedade, bem como mobiliza, estrutura e divulga modelos para a compreensão dessas "realidades". Um dos elementos centrais desta intervenção sobre as categorias de percepção reside no espelho que mostra cada um (cada país) na sua relação e na sua posição relativa a outros. Como já foi referido atrás, a comparação situa os decisores políticos numa imaginada linha do tempo, que vai da sociedade industrial à sociedade do conhecimento e que se desenrola num espaço competitivo-cooperativo mundial. A comparação internacional é um lugar onde se exerce a imaginação de uma sociedade transnacional (traçando para os indivíduos um quadro comum de expectativas de performance e de empenhamento na vida social, a partir da confiança depositada na expertise científica) e no qual se constrói uma polity transnacional (na qual os Estados nacionais, voluntariamente, se envolvem com outras instâncias na produção conjunta de regras). Assim, a agência da OCDE não produz apenas sentidos e conteúdos para as políticas nacionais, não actua apenas como fonte de regulação dessas políticas "nacionais". Ela produz também um conjunto de regras para a regulação política dos reguladores das políticas.

Paralelamente, estas comparações constituem instrumentos para o exercício do governo e para o seu escrutínio a uma escala nacional. Deste ponto de vista, a imagem que o "espelho" devolve é, em si mesma, um discurso de poder, tanto por via da culpabilização e da responsabilização, quanto por via da esperança, do optimismo e da confiança 
na possibilidade de reforma que verte sobre os políticos e as políticas nacionais. Instrumentos como o PISA constituem recursos valiosos para pensar e agir ou para legitimar a acção, tendo em conta a reputação, por um lado, de objectividade face à realidade e, por outro, de exterioridade face aos interesses de que esse tipo de saber é portador nas nossas sociedades. É de supor que os políticos nacionais dificilmente dispensem os produtos de agências, que são percebidas como estruturas independentes e de expertise. Agências estas que lhes fornecem recursos para pensarem a realidade educacional e para expressarem as suas orientações, mas que o fazem, porém, em nome da "independência” e do "cosmopolitismo" do saber dos peritos.

\section{Recebido e aprovado em outubro de 2009.}

\section{Notas}

1. Na realização dessa pesquisa, contamos com a colaboração constante - e essencial para a concretização do estudo - da doutoranda e bolseira de investigação Estela Costa (em matéria de recolha e tratamento da informação nas várias dimensões da pesquisa) e com o contributo das equipas Knowandpol do sector da educação (que elaboraram pequenos relatórios sobre a participação dos actores nacionais nas estruturas supranacionais do PISA) e, ainda, da investigadora Ana Lúcia Fernandes (no tratamento e análise desses relatórios).

2. Para um detalhado informe sobre o surgimento do PISA e sobre as micropolíticas desse processo, veja-se Morgan (2007).

3. As controvérsias têm envolvido questôes bem diversas: umas são relativas ao projecto comparatista, no qual este tipo de estudo se inscreve; outras versam as metodologias seguidas, seja num plano mais crítico da possibilidade mesmo de comparabilidade, seja no plano das limitações ou deficiências das escolhas relativas a procedimentos de construção, recolha, tratamento e análise; outras relacionam-se com o tipo de recepção e de uso dado aos resultados por parte de políticos e dos media; e outras ainda debatem a pertinência do investimento financeiro face aos resultados que oferece e aos efeitos que provoca nos países participantes (Mons, 2007; ver também Carvalho, 2009).

4. Por exemplo, contrastando a natureza do trabalho e seus papéis típicos: "actividade física" versus "actividade mental"; "transformação de objectos materiais" versus "recolha de informação e resolução de problemas"; "tarefas prescritas e actividades rotineiras" versus "tarefas não-rotineiras; "baixos níveis de interacção" versus "altos níveis de interacção"; "papéis resistentes à mudança" versus "papéis frequentemente e substancialmente redefinidos” (Weers \& Kerchner, 1996, p. 146).

5. De acordo com Gagnon (1990, p. 2-6), o modelo "racionalista" compreende os seguintes elementos centrais: os "dados e os resultados" das pesquisas constituem "um novo conhecimento", baseado em "cânones metodológicos especializados", produzido para dar fundamentação racional, objectiva, à decisão política e para resolver "problemas 
políticos" relevantes; por fim, compete aos experts serem capazes de mediar entre o conhecimento objectivo criado e os interesses políticos.

6. Trecho de entrevista a membro do Secretariado do PISA, conduzida no âmbito da pesquisa sobre a fabricação supranacional do Programa (ver Carvalho, 2009).

\section{Referências}

ALASUUTARI, P. The governmentality of consultancy and cooperation: the influence of OECD. Paper presented at the $37^{\text {th }}$ World Congress of the International Institute of Sociology. Stockholm, Jul. 5-9, 2005 .

BARROSO, J.; CARVALHO, L.M. PISA: un instrument de régulation pour relier des mondes. Revue Française de Pédagogie, Paris, n. 164, p. 177-180, 2009 .

BOTTANI, N. La más bella del reino: el mundo de la educación en alerta con la llegada de un príncipe encantador. Revista de Educación, Madrid, n. extra, p. 75-90, mar. 2006.

BROADFOOT, P. Comparative education for the $21^{\text {st }}$ Century: retrospect and prospect. Comparative Education, Oxford, v. 36, n. 3, p. 357-371, 2000.

CARVALHO, L.M. [com Estela Costa]. Production of OECD's 'Programme for International Student Assessment. Knowandpol Orientation 3 - Supra-national Instruments - WP 11 Report (Education). Apr. 2009. Disponível em: <www.knowandpol.eu/>

CARVALHO, L.M.; AFONSO, N.; COSTA, E. PISA: fabrication, circulation and use in 6 European countries. Knowandpol Orientation 3 - Supra-national Instruments - Integration Report (Education) WP 17. Oct. 2009. Disponível em: <www.knowandpol.eu/>

DELVAUX, B.; MANGEZ, E. (Ed.). Literature reviews on knowledge and policy. Knowandpol Literature Review - Report 1. June, 2007. Disponível em: <www.knowandpol.eu/>

DELVAUX, B.; MANGEZ, E. Towards a sociology of the knowledgepolicy relation. Knowandpol literature review - integrative report. Sept. 2008. Disponível em: <www.knowandpol.eu/> 
Governando a educação pelo espelho do perito...

FOSHAY, A.W. (Ed.). Educational achievements of thirteen-year-olds in twelve countries. Hamburg: UNESCO Institute for Education, 1962.

GAGNON, A.-G. The influence of social scientists on public policy. In: Brooks, S.; Gagnon, A.-G. (Ed.). Social scientists, policy, and the State. New York: Praeger, 1990. p. 1-17.

GREK, S. Governing by numbers: the PISA effect. Journal of Education Policy, London, v. 24, n. 1, p. 23-37, 2009.

HENRY, M. et al. The OECD, globalization and education policy. Oxford: Pergamon, 2001.

HUGGONNIER, B. Les acquis des adolescents. Futuribles, Paris, n. 344, p. 47-61, 2008.

HUSÉN, T.; POSTLETHWAITE, T.N. A brief history of the International Association for the Evaluation of Educational Achievement (IEA). Assessment in Education, London, n. 3, p. 129-141, 1996.

JACOBSON, B. Regulated regulators. In: DJelic, M.-L.; SAHLinAnderson, K. (Ed.). Transnacional governance: institutional dynamics of regulation. Cambridge: Cambridge University, 2006. p. 205-224.

JACOBSON, B.; SAHLIN-ANDERSON, K. Dynamics of soft regulations. In: Djelic, M.-L.; SAhlin-Anderson, K. (Ed.). Transnacional governance: institutional dynamics of regulation. Cambridge: Cambridge University, 2006. p. 247-266.

LASCOUMES, P.; LE GALÈS, P. L'action publique saisie par ses instruments. In: Lascoumes, P.; Le Galès, P. (Dir.). Gouverner par les Instruments. Paris: Science Po, 2004. p. 13-44.

LATOUR, B. Joliot: a história e a física misturadas. In: Sèrres, M. (Dir.). Elementos para uma história das ciências. Lisboa: Terramar, 1996 [orig. 1989]. v.3, p. 131-155.

LEUZE, K.; MARTENS, K.; RUSCONI, A. New arenas of education governance: the impact of international organizations and markets on education policy making. In: Martens, K.; Rusconi, A.; Lutz, K. (Ed.). Transformations of the state and global governance. London: Routledge, 2007. p. 3-15. 
LINDBLAD, S.; POPKEWITZ, T.S. Educational restructuring: (re) thinking the problematic of reform. In: Lindblad, S.; Popkewitz, T.S. (Ed.). Educational restructuring: perspetives on traveling policies. [S.1.]: Information Age, 2005.

LINDQUIST, E.A. The third community, policy inquiry, and social scientists. In: Brooks, S.; GaGnon, A.-G. (Ed.). Social scientists, policy, and the State. New York: Praeger, 1990. p. 21-51.

MAHON, R.; McBRIDE, S. The OECD and transnational governance. Vancouver: UBC, 2008.

MANGEZ, E. Knowledge economy, knowledge policy and knowledge regimes In: Delvaux, B.; Mangez, E. Towards a sociology of the knowledge-policy relation. Knowandpol literature review - integrative report. Sept. 2008. p. 99-118. Disponível em: <www.knowandpol.eu/>

MONS, N. L'évaluation des politiques éducatives: apports, limites et nécessaire renouvellement des enquêtes internationales sur les acquis des élèves. Revue Internationale de Politique Comparée, Bruxelles, v. 14, n. 3, p. 409-423, 2007.

MORGAN, C. The OECD Programme for International Student Assessment: unraveling a knowledge network. 2007. Thesis (Doctoral) - School of Public Policy and Administration, Carleton University, Ottawa.

NAHESSI, A. Making knowledge observable: short considerations about the practice of "doing knowledge". Note for Knowandpol, 2008. (não publicado).

NOAKSSON, N.; JACOBSSON, K. The production of ideas and expert knowledge in OECD: the OECD Jobs Strategy in contrast with the EU employment strategy. Stocholm: Score, 2003.

NÓVOA, A. Modèles d'analyse en éducation comparée: le champ et la carte. In: NóvoA, A. Histoire et comparaison. Lisboa: Educa, 1998, p. 51-84.

NÓVOA, A. Ways of thinking about education in Europe. In: NóvoA, A.; LAWN, N. (Ed.). Fabricating Europe: the formation of an education space. Dordrecht: Kluwer, 2002, p. 131-155. 
Governando a educação pelo espelho do perito...

NÓVOA, A.; TARIV-MASHAL, T. Vers un comparatisme critique. Lisboa: Educa, 2003.

NOWOTNY, H.; SCOTT, P.; GIBBONS, R. Re-thinking science: knowledge and the public in the age of uncertainty. Cambridge: Polity, 2001.

ORGANISATION FOR ECONOMIC CO-OPERATION AND DEVELOPMENT (OECD). PISA: the OECD Programme for International Student Assessment. [Brochura PISA]. [s.d.]. Disponível em: <www.pisa. oecd.org/dataoecd/51/27/37474503.pdf>.

ORGANISATION FOR ECONOMIC CO-OPERATION AND DEVELOPMENT (OECD). Measuring student knowledge and skills: a new framework for assessment. Paris, 1999.

ORGANISATION FOR ECONOMIC CO-OPERATION AND DEVELOPMENT (OECD). Knowledge and skills for life: first results from PISA 2000. Paris, 2001.

ORGANISATION FOR ECONOMIC CO-OPERATION AND DEVELOPMENT (OECD). The PISA 2003 assessment framework: mathematics, reading, science and problem solving knowledge and skills. Paris, 2003.

ORGANISATION FOR ECONOMIC CO-OPERATION AND DEVELOPMENT (OECD). Learning for tomorrows world: first results from PISA 2003. Paris, 2004.

ORGANISATION FOR ECONOMIC CO-OPERATION AND DEVELOPMENT (OECD). Assessing scientific, reading and mathematical literacy: a framework for PISA 2006. Paris, 2006.

ORGANISATION FOR ECONOMIC CO-OPERATION AND DEVELOPMENT (OECD). PISA 2006: sciences competencies for tomorrows world. Paris, 2007.

OZGA, J.; GREK, S. Governing by numbers. Paper presented to the European Sociological Association Annual Conference, Network 10, Glasgow, Sept. 2007.

POPKEWITZ, T.S. Preface. In: Popkewitz, T.S. (Ed.). Educational knowledge: changing relations between the State, civil society and the 
educational community. New York: State University of New York, 2000. p. vii-x.

POSTLELTHWAITE, T.N. Overview of issues in international achievement studies. In: JaWOrski, B.; Phillips, D. (Ed.). Comparing standards intenationally. Oxford: Symposium Books, 1999. p. 23-59.

RAUTALIN, M.; ALASUUTARI, P. The curse of success: the impact of OECD's Programme for International Student Assessment on the discourses of the teaching profession in Finland. European Educational Research Journal, Oxford, v. 6, n. 4, p. 348-63, 2007.

RINNE, R.; KALLO, J.; HOKKA, S. Too eager to comply?: OECD education policies and the finnish response. European Educational Research Journal, Oxford, v. 3, n. 2, p. 454-86, 2004.

ROCHEX, J.Y. Introduction [Dossier PISA: analyses secondaires, questions et débats théoriques et méthodologiques]. Revue Française de Pédagogie, Paris, n. 157, p. 5-9, 2006.

RUTKOWSKI, D.J. "Converging us softly": how intergovernmental organizations promote neoliberal educational policy. Critical Studies in Education, London, v. 48, n. 2, p. 229-247, 2007.

SCHLEICHER, A. Fundamentos y cuestiones políticas subyacentes al desarollo de PISA. Revista de Éducación, Madrid, n. extra, p. 21-43, 2006.

SCHLEICHER, A. Can competencies assessed by PISA be considered the fundamental school knowledge 15-year-olds should possess? Journal of Educational Change, Dordrecht, v. 8, n. 4, p. 349-357, 2007.

STAR, S.-L.; GRIESEMER, J.R. Institutional ecology, "translation" and "boundary objects". In: BIAGIOLI, M. (Ed.). The science studies reader. New York: Routledge, 1999 [orig. 1989]. p. 505-524.

WEINBERG, M. Medir para avançar rápido. Entrevista: Andreas Schleicher. Veja, São Paulo, p. 17, 20-21, Entrevista, ago. 2008. Disponível em: <veja.abril.com.br/060808/>

STEINER-KHAMSI, G. The politics of league tables. Journal of Social Science Education, n. 1, p. 1-6, 2003. Disponível em: <www.jsse.org/ 2003-1/tables_khamsi.htm> 
STEINER-KHAMSI, G. Blazing a trail for policy theory and practice. In: SteIner-Khamsi, G. (Ed.). The global politics of educational borrowing and lending. New York: Teachers College, 2004. p. 201-220.

VAN ZANTEN, A. Le rôle de la connaissance dans la régulation du système educatif en France: de la production à la réception. Communication presentée au Colloque en hommage des 40 ans de la Direction de l'Évaluation et de la Prospective, Oct. 2004.

WEERS, J.; KERCHNER, C. This time it's serious: post-industrialism and the coming change in education. In: Crowson, R.L.; BOYD, W.L.; MaWhinney, H.B. (Ed.). The politics of education and the new institutionalism. London: Falmer, 1996. p. 135-151. 